\title{
Food recommendations for abnormal uterine bleeding in Traditional Iranian medicine on the basis of Hemorheology
}

\author{
Review Article
}

\section{Golamreza salsali $^{1}$, Nafise Zafarghandi ${ }^{2}$, Fatemeh Nojavan ${ }^{3 \text { and } 4}$, Atieh Sadat Danesh ${ }^{3 *}$}

1. Department of Traditional Iranian Medicine, Shahed University, Tehran, Iran.

2. Department of Obstetrics and Gynecology Medical Science, Shahed University, Tehran, Iran.

3. Department of Traditional Iranian Medicine, Qom University of Medical Sciences, Qom, Iran.

4. Health and Spiritual research Center, Qom University of Medical Sciences, Qom, Iran.

\begin{abstract}
Abnormal uterine bleeding is one of the most common problems in pre-menopausal women. Traditional Iranian Medicine has given numerous reasons for this problem. Some of these problems are focused upon the rheological changes that show up in the blood. Food recommendations are one of the first therapeutic measures in Traditional Iranian Medicine and determination of the type of patient's diet is an integral part of the therapeutic protocols of this medicine. This article intends to review the books of Traditional Iranian Medicine in addition to the nutritional recommendations of this science in abnormal uterine bleeding and explain their effect on changes in blood rheology. For this purpose, the texts of Iranian Medicine related to different ages were searched and dietary recommendations in abnormal uterine bleeding were extracted. From this point of view, some changes in the quality or quantity of blood, according to the science of fluid mechanics, increases fluidity of blood. The recommended diets in Traditional Iranian Medicine to correct these changes will help control and cure this problem.
\end{abstract}

Keywords: Dietary recommendations, Abnormal uterine bleeding, Traditional Iranian medicine, Hemorheology, blood rheology .

\section{Introduction:}

Abnormal Uterine Bleeding (AUB) is a menstrual bleeding that occurs in abnormal amount, duration and regularity and occurs in non-pregnant women at pre-menopausal age (1).

Abnormal uterine bleeding has three patterns: acute, chronic and intermenstrual.

- Acute AUB is defined as episode of heavy menstrual bleeding which requires the help of a doctor (2).

In this definition the term 'heavy menstrual bleeding' refers to excessive menstrual blood loss which interferes with a woman's physical, social, emotional and/or material quality of life. This definition is sufficient in clinical evaluations. But in research studies that require measurement tools, bleeding more than $80 \mathrm{cc}$ daily or for more than 8 days is considered as a severe uterine bleeding $(1,3)$.

- Chronic AUB is called uterine bleeding, which

*Corresponding Author:

\section{Atieh Sadat Danesh,}

Department of Traditional Iranian Medicine,

Qom University of Medical Science.

Qom, Iran.

E-mail: atdanesh@muq.ac.ir is abnormal in terms of quantity and period and order and lasts more than 6 months (2).

- Intermenstrual bleeding is the bleeding that occurs between menstrual cycles. Menstrual bleeding may not be high in the last two categories (2).

More than $30 \%$ of women find it necessary to get medical treatment because of this problem. Acute severe menstrual bleeding can cause severe anemia and require emergency care (4).

AUB also imposes economic burdens on individuals as well as society (5).

Abnormal uterine bleeding is classified according to the causes of structural and nonstructural categories, all of which are summarized as Palm-Coien, Polyps, Adenomyosis, Leiomyosis, Malignancy-Coagulopathy, Ovulatory disorder, Iatrogenic, Endometrial and Not Classified. (6).

Treatments in new medical science include surgical and medicinal treatments. Apart from the fact that each of these treatments has its own complications, in many cases treatment is not considered definitive and there is a possibility that the real problem may show up again (3).

One of the most important ways to reduce the use of drugs and to avoid their complications in the treatment of diseases is to pay attention to the nutrition of the patient. The dietary regimen improves the health 
outcome by adjusting the intake of food in terms of quality and quantity.

Special diets have been recommended in the current medical science for many diseases, including heart disease and diabetes, thyroid, malignancies (15-7). Today, in women's diseases, including abnormal uterine bleeding, although a series of clinical trials have been taken on some foods but there is no definite diet (23-16). Basically, nutritional guidelines are established in each disease based on knowledge of the causes and the exacerbating factors of that disease.

Treatment and management of diseases have been of great concern to human beings from old days. In this regard, doctors and scientists of Traditional Iranian medicine have paid special attention to this issue. Rhazes, an Iranian scientist (925-855 BC), believed that as far as food can be used for cure, medicine should not be used (24). In terms of Traditional Iranian medicine, food delivery to patients is considered as one of the pillars and therapeutic programs, and it is not merely a subsidiary side, and a great deal has been written about the issue of patient nutrition (24). What is necessary to be benefitted by these food suggestions is to know how the Iranian medical science looks at the causes of abnormal uterine bleeding. This paper, while expressing the etiology of this disease from the viewpoint of Iranian medical science and suggested dietary recommendations, refers to the relation between some of these instructions and blood rheology.

\section{Materials and methods}

In this study, the authentic texts of Traditional Iranian medicine related to different ages, such as the Canon of Medicine of a, the Tebb-e-akbari of Arzani, Moalejat of Aghili Khorasani, Sharh Al-Asbaab of Samarghandi, Exir-e Azam of Nazem Jahan were put to research and matter related to the increase in menstrual bleeding, including the definition, causes and dietary recommendations were extracted. Then, considering that one of the causes of unnatural menstrual bleeding was focused on blood changes and its effect on blood flow behavior by searching for authoritative electronic sources such as Science Direct, Scopus, web of science, PubMed with the keywords Rheology, Hemorheology, Blood rheology, the rheological performance of blood was studied based on the latest scientific findings. Finally, the Iranian dietary guidelines for uterine bleeding were presented based on the principles of fluid mechanics.

\section{Results}

In Traditional Iranian medicine, abnormal uterine bleeding is associated with an increase in bleeding in the menstrual cycle, or prolonged menstrual periods of more than 7 days, or bleeding between menstrual periods. (25) In this view, abnormal uterine bleeding is categorized based on the causative factors, and a specific treatment recommendation is given for each group (25-30). Although abnormal uterine bleeding in Traditional Iranian medicine is very similar to new medicine in terms of definition, it is slightly different from the causes, and this difference is the result of the unique view of Traditional Iranian medicine. According to this view, the cause of abnormal uterine bleeding is either due to changes in blood rheology or due to uterine causes (25-31).

\section{AUB due to changes in blood rheology}

According to the rules of mechanics, when a parallel force is applied to the surface of the material, it causes deformation or displacement in that material. This force is referred to as shear stress and refers to the amount of displacement or deformation shear strain (shear rate) refers to. When we say that flow of the material is high, it means its shear rate is high. The resistance to flow or deform a material (shear rate) is called the viscosity of the material. In other words, the higher the viscosity the less is fluidity. Various factors cause changes in viscosity, which include temperature and pressure transplantation between components of a fluid; the viscosity decreases with increasing temperature and increases with increasing pressure. The more the cohesion between the components of a fluid the higher is its viscosity (32).

Blood is a fluid which is composed of various components so that in addition to the above factors its viscosity also depends upon these components. The viscosity of the blood changes with the change in size and shape and the density of its components. Any factor that eliminates its components, such as adding some substances, such as water, or rising temperatures, reduces the viscosity of the blood, and anything that causes the condensation of its components, such as lowering of temperature, increasing hematocrit, the accumulation of red blood cells (RBCs), aggregation and the addition of acute phase proteins in some diseases increase the viscosity of the blood $(32,33)$.

From the perspective of Traditional Iranian medicine, any factor that increases blood fluidity can cause bleeding, including uterine bleeding. This agent can show its effect by changing the quality or quantity of blood.

\section{Changes in blood quality}

Changes in blood quality in two ways can lead to uterine bleeding:

Increase in proportion of water with respect to other blood components:

As the percentage of water increases in solid materials of blood, its viscosity decreases and the blood becomes smoother. In Traditional Iranian medicine, this is called increased blood watery part or "maiyat". In this case, the menstrual blood is diluted without heat and irritation; it is seen in women who have many uterine secretions during non-menstrual days. In these cases, foods should be used that make the blood 
concentrated by reducing the percentage of water contained in it. These foods are called 'drying foods' in Traditional Iranian medicine, including cooked peas and grilled meat. The recommended meat in these cases is a young chicken meat in which baking cinnamon, cumin and saffron have been added (24-29).

\section{Increase in blood temperature}

Reduction in the viscosity of blood due to the increase in its temperature as well as its fluidity can be one of the causes of bleeding. Identification of the blood released during menstruation is possible. The released blood is thin and yellowish, hot and burning, and releases with a gush. An appropriate step to take in this situation is to bring down the blood temperature. By lowering the blood temperature its dilution decreases. Therefore, such food items are used which are called as 'coolers' in Traditional Iranian medical science- foods in which pomegranate, barberry, sour grape, rhubarb, sumac and vinegar are used. And food that reduces blood thinning as well as temperature, such as rice cooked with vinegar or barberry, or pomegranate, or sumac, or vinegar, or egg yolks cooked in vinegar. Similarly, to increase blood's thickness, starch can also be added in food. Among the food items which are 'coolers' as well as make the blood thick is peeled lentil especially cooked with vinegar (25-30).

\section{Change in blood quantity}

One of the changes that cause an increase in uterine bleeding is hyperemia (25-30). Based on Traditional Iranian medical science hyperemia happens in people who complain of overeating and consuming products that make blood, as well as seeking rest. There are effects of hyperemia such as facial redness, heavy feeling in the body, and a full pulse in the patient. These people feel comfortable after bleeding, but severe uterine bleeding disrupts their life (26). This increase in blood can be due to increased blood pressure or increased hematocrit. The higher the blood flow, the greater is the shear stress in the vessels, which causes bleeding and damage to the blood vessels, such as cerebral hemorrhage that occurs in high blood pressure due to the tear of capillaries $(33,34)$. In such cases it is recommended to decrease the patient's diet and such diets should be given which on one hand should satisfy his hunger and on the other hand produce less blood such as meatless pottage with rice or barley or lentil or mung with vegetables such as spinach or coriander or pumpkin and tasting with barberry or sour grape or pomegranate juice or sour yogurt. These pottages are called "mozavvere" food in Traditional Iranian medicine (25-30).

\section{AUB with uterine causes}

The causes of uterine bleeding include lesions such as ulcers, mass, trauma and dystocia, and any factor that causes damage to the uterus. In these cases, in addition to treating the cause of bleeding, it is advisable to consume astringent food. These materials, which have astringent properties, cause the uterus to accumulate and the closure of the vessel and stoppage of bleeding. These foods include quince, apple, lentil, sumac, sour grape, pomegranate, barberry, oak, Russian olive and vinegar $(25$ - 30) (Table 1).

Table 1: Advisable to consume astringent food

\begin{tabular}{|l|l|l|l|}
\hline \multicolumn{2}{|c|}{$\begin{array}{c}\text { Uterine bleeding as per the cause } \\
\text { (according to the Traditional } \\
\text { Iranian medical science) }\end{array}$} & Characteristics of diet & \multicolumn{1}{c|}{ Example } \\
\hline $\begin{array}{l}\text { Blood } \\
\text { causes }\end{array}$ & $\begin{array}{l}\text { Diluted blood due } \\
\text { to its high } \\
\text { temperature }\end{array}$ & $\begin{array}{l}\text { Coolant + Astringent }+ \\
\text { Thickener }\end{array}$ & $\begin{array}{l}\text { Barberry, Pomegranate, sour grape, Sumac, } \\
\text { rhubarb, Vinegar Starch, Rice } \\
\text { Or egg yolk + vinegar } \\
\text { Peeled lentil + Vinegar }\end{array}$ \\
\cline { 2 - 4 } & $\begin{array}{l}\text { Diluted blood due } \\
\text { to an increase in } \\
\text { its watery part. }\end{array}$ & $\begin{array}{l}\text { Dried Food + Aromatic } \\
\text { and Digestive spices }\end{array}$ & $\begin{array}{l}\text { Cooked peas, grilled meat + saffron, cumin, } \\
\text { cinnamon }\end{array}$ \\
\cline { 2 - 4 } & $\begin{array}{l}\text { Increase in blood } \\
\text { quantity }\end{array}$ & $\begin{array}{l}\text { Foods that produce little } \\
\text { blood }\end{array}$ & $\begin{array}{l}\text { Meatless porridges containing rice or barley } \\
\text { or lentils or mung + spinach or coriander or } \\
\text { pumpkin + barberry or sour grape or } \\
\text { pomegranate juice or sumac or sour yogurt }\end{array}$ \\
\hline $\begin{array}{l}\text { Uterine } \\
\text { causes }\end{array}$ & $\begin{array}{l}\text { Mass, ulcer, } \\
\text { trauma and } \\
\text { injuries, weakness } \\
\text { of uterine tissue. }\end{array}$ & Astringent foods & $\begin{array}{l}\text { Quince, apple, lentil, sumac, sour grape, } \\
\text { pomegranate, barberry, oak and vinegar }\end{array}$ \\
\hline
\end{tabular}




\section{Discussion}

According to Traditional Iranian medicine, normal menstrual blood in terms of quality and quantity shows a woman's body health mark $(25,35)$. Therefore, in the event of a change, it should be corrected in terms of quality and quantity, which is the first step in nutritional reform. The unique approach of Traditional Iranian medicine towards uterine bleeding highlights the knowledge of the ancient Traditional Iranian scientists about uterine histology, its anatomy and high blood supply and possible pathologies in it.

The cause of many diseases in Traditional Iranian medicine is a change in the blood that the association of these changes and uterine bleeding with the present-day hemorheology knowledge is justifiable. Although the scientific justification for these changes requires more scientific research, but with an approach based on the principles of Traditional Iranian medicine, uterine bleedings, which are now "NOT CLASSIFIED" for reasons of prevention, have been adopted. With a superficial look at the recommended diets for any of the causes of uterine bleeding, it appears that the items of many of the dietary foods are common. Although the anti-hemorrhagic properties of many of these substances, such as quince, barberry, Russian olive, lentil, now proven through a clinical trial (17-22), But what matters in prescribing food and medicine in Traditional Iranian medicine is eliminating the causative agent. In this way, in addition to the same dietary instructions that include the consumption of astringent foods in all kinds of bleeding and strengthening the body with a tonic food in the event of a weakness due to the loss of blood, special dietary recommendations based on the cause of uterine bleeding should be recommended. Other than the quality of astringent foods in terms of warmth and cold, they play a basic role in curing different bleeding. In this way in some types of uterine bleeding, they are part of the early stages of the treatment, and in some others after the bleeding is resolved. Because according to the Traditional Iranian medicine view, all astringent materials can strengthen the organ, and in the uterine bleeding, there is a risk of weakness in the uterus. Recent studies have also shown that astringent substances contain tannins and flavonoids that decrease the intensity of inflammation by affecting prostaglandins (36).

Apart from the pathological cases mentioned, in some women, the uterine bleeding is more than normal, but the person does not feel uncomfortable and weak and feel comfortable after the blood flows out. In other words, in laboratory tests performed on the patient, no disorder in blood factors, including the amount of hemoglobin, has been observed and has not adversely affected the quality of life of the patient. Because, according to Traditional Iranian medicine, uterus, in addition to being one of the reproductive organs, is one of the body's excretory organs. Traditional Iranian medicine recognizes this bleeding as a means of disposing of waste materials and exhaust from the body through menstrual blood. There is no need to take an action to stop the bleeding (25 - 30).

Important point in nutritional management of patients with abnormal uterine bleeding is avoiding consumption of foods that increase uterine bleeding. Among these are spicy spices, spicy veggies like leek, onions, garlic, celery, cooked cabbage, beans, fenugreek and sesame.

Conclusion: Consideration of nutrition in the management of abnormal uterine bleeding is very important, although some foods are effectiveness for stopping bleeding, but in applying nutritional measures to control uterine bleeding, it is necessary to pay attention to the following three principles:

1. The food should be chosen with the intention to eliminate the causative agent of bleeding and, at least, it should not increase the trigger factor. In these cases, avoiding some foods play a more significant role.

2. Astringent food in all cases of uterine bleeding can be effective.

3. Considering the strengthening of the body by consuming nutritious and easy to digest food, it should be considered in cases of weakness caused by excessive uterine bleeding.

Considering the comprehensive view of traditional Iranian medicine for the treatment of uterine bleeding and the dietary recommendations provided, it is necessary to put them to test and extract a therapeutic protocol.

\section{References}

1. Whitaker L, Critchley H. Abnormal uterine bleeding. Best Practice \& Research Clin Obstet \& Gynecology. 2016; 34: 54-65. Doi: 10.1016/ j.bpobgyn.2015.11.012

2. Munro M.G, Critchley H, Fraser IS. The FIGO classification of causes of abnormal uterine bleeding in the reproductive years. Fertility and sterility. 2011; 95: 2204-8. DOI: 10.1016/ j.fertnstert.2011.03.079

3. Chodankar R, Harpur A, Mahmood T. Heavy menstrual bleeding. Obstetrics, Gynecology \& Reproductive Medicine. 2016; 28: 196-202.

4. Singh S, Best C, Dunn S, Leyland N, Wolfman W.L. No. 292-Abnormal Uterine Bleeding in PreMenopausal Women. J Obstet Gyneco Can. 2018; 40: e391-e415. Doi: 10.1016/j.jogc.2018.03.007

5. Zauberman YL, Pourcelot AG, Capmas P, Fernandez H. Update on the management of abnormal uterine bleeding. Journal of Gynecology Obstetrics and Human Reproduction. 2017; 46: 613 -622 . 
6. Malcolm G. Practical aspects of the two FIGO systems for management of abnormal uterine bleeding in the reproductive years. Best Practice \& Research Clin Obstet \& Gynecology. 2017; 40: 322.

7. Sangita S, Vik SA, Pakseresht M, Kolonel LN. Adherence to recommendations for fruit and vegetable intake, ethnicity and ischemic heart disease mortality. Nutrition, Metabolism and Cardiovascular Diseases. 2013; 23: 1245-1254. https://doi.org/10.1016/j.numecd.2013.03.004

8. Mann J. 23- Ischemic Heart Disease in Vegetarians and Those Consuming a Predominantly Plant-Based Diet. In: François M, Editor. Vegetarian and PlantBased Diets in Health and Disease Prevention, Dunedin: Academic Press. 2017, P. 415-427. https://doi.org/10.1016/B978-0-12-803968-7.00023$\mathrm{X}$

9. Garla P, Waitzberg DL, Tesser A. Nutritional Therapy in Gastrointestinal Cancers. Gastroenterology Clinics of North America. 2018; 47: 231-242. https://doi.org/10.1016/ j.gtc.2017.09.009

10. Cioara T, Anghel I, Salomie I, et al. Expert system for nutrition care process of older adults. Future Generation Computer Systems. 2018; 80: 368-383. https://doi.org/10.1016/j.future.2017.05.037

11. Chiu THT, Pan WH, Lin MN, Lin CL. Vegetarian diet, change in dietary patterns, and diabetes risk: A prospective study. Nutrition and Diabetes. 2018; 8 (12). DOI: 10.1038/s41387-018-0022-4

12. Gholizadeh F, Moludi J, Lotfi Yagin N, et al. The relation of Dietary diversity score and food insecurity to metabolic syndrome features and glucose level among pre-diabetes subjects. Primary Care Diabetes. 2018; 12: 338-344. https:// doi.org/10.1016/j.pcd.2018.03.003

13. Mahan LK, Escott-Stump S. Krause's food, nutrition, \& diet therapy. 14th ed. Saunders Philadelphia. 2017.

14. Iacovides S, Meiring R. The effect of a ketogenic diet versus a high-carbohydrate, low-fat diet on sleep, cognition, thyroid function, and cardiovascular health independent of weight loss: study protocol for a randomized controlled trial. Trials. 2018; 19: 62(62). https://doi.org/10.1186/ s13063-018-2462-5

15. Rosenthal RL. Effectiveness of altering serum cholesterol levels without drugs. Proceedings (Baylor University Medical Center). 2000; 13: 351355. doi.org/10.1080/08998280.2000.11927704

https://

16. Schliep KC, Zarek SM, Schisterman EF, et al. Alcohol intake, reproductive hormones, and menstrual cycle function: a prospective cohort study. The American Journal of Clinical Nutrition. 2015; 102: 933-942. https://doi.org/10.3945/ ajcn.114.102160

17. Zhou W, Abdurahman A, Umar A, et al. Effects of Cydonia oblonga Miller extracts on blood hemostasis, coagulation and fibrinolysis in mice, and experimental thrombosis in rats. Journal of Ethnopharmacology. 2014; 154: 163-169. https:// doi.org/10.1016/j.jep.2014.03.056

18. Rahia P, Mirghafourvand M, Mohammad-AlizadehCharandabi S, Javadzadeh Y, Seidi S . Comparison of the effect of mefenamic acid and quince on the level of menstrual bleeding and hemoglobin. European Journal of Integrative Medicine. 2016; $8 \quad: 67-72 . \quad$ https://doi.org/10.1016/ j.eujim.2015.11.022

19. Berenji Ardestani S, Sahari MA, Barzegar M. Effect of extraction and processing conditions on organic acids of barberry fruits. Journal of food biochemistry. 2015; 39: 554-565. https:// doi.org/10.1111/jfbc. 12158

20. Nabavizadeh MR, Zargaran A, Moazami F, et al. Comparison of the Hemostatic Activity of Quercus persica Jaub. \& Spach. (Oak) With Ferric Sulfate in Bony Crypts. Journal of Evidence-Based Complementary \& Alternative Medicine. 2016; 21: 34-38. DOI: $10.1177 / 215658721559337$

21. Hamidpour R, Hamidpour S, Hamidpour M, et al. Russian olive (Elaeagnus angustifolia L.): From a variety of traditional medicinal applications to its novel roles as active antioxidant, anti-inflammatory, anti-mutagenic and analgesic agent. Journal of Traditional and Complementary Medicine. 2017; 7: 24-29. https://doi.org/10.1016/j.jtcme.2015.09.004

22. Zhang B, Deng Z, Tang Y, et al. Effect of domestic cooking on carotenoids, tocopherols, fatty acids, phenolics, and antioxidant activities of lentils (Lens culinaris). J. Agric. Food Chem. 2014; 62: 1258512594. DOI: $10.1021 / \mathrm{jf504181 \textrm {r }}$

23. Abu-Reidah IM, Jamous RM, Ali-Shtayeh MS. Phytochemistry, Pharmacological Properties and Industrial Applications of Rhus coriaria L. (Sumac). Jordan Journal of Biological Sciences. 2014; 7: 233244. DOI: $10.12816 / 0008245$

24. Nikaein F, Zargaran A, Mehdizadeh A. Rhazes' concepts and manuscripts on nutrition in treatment and health care. Anc Sci Life. 2012; 31: 160-163. Dol: 10.4103/0257-7941.107357

25. Arzani MA. Tebb-e-akbari. Second ed. Tehran: Republished by Institute of Medical History, Iran University of Medical Sciences; 2009. P 961.

26. Nejatbakhsh. F. Principles of nutrition in diseases based on principles Iranian Traditional Medicine. Tehran: Choogan; 2013.

27. Avicenna, Canon of Medicine (Al-Qanun fi Tib). Third ed. Beirut: Dar Al Ehya Al Toras Al Arabi; 2005. P 470.

28. Cheshti MA. Exir-e Azam (Azam's Elixir). Third ed. Tehran: Iran University of Medical Science, 
Institute for Islamic and Complementary Medicine; 2007. P 703.

29. Aghil SMH, Moalejate Aghili. Tehran: Iran University of Medical Science; 1260 AH. P 771.

30. Samarghandi N. Sharh-al-Asbab Val-Alamat. In: N Kermani, Editor. Resuscitation of natural medicine Institute. Qom; 2008.Vol 2. P 239.

31. Tansaz. M, Memarzadehzavareh. H, Qaraaty. M., Eftekhar. M, Tabarrai. M, Kamalinejad. M., Menorrhagia Management in Iranian Traditional Medicine, Journal of Evidence-Based Complementary \& Alternative Medicine. 2016; 21 : 71-76. DOI: $10.1177 / 215658721558952$

32. Baskurt. O.K, Meiselman. H.J, Blood rheology and hemodynamics, Seminars in thrombosis and hemostasis. 2003; 9: 435-450. DOI: $10.1055 / \mathrm{s}-2003$ $-44551$
33. Fu. G.X, Ji. M, Han. L.Z, et al, Erythrocyte rheological properties but not whole blood and plasma viscosity are associated with severity of hypertension in older people, Zeitschrift für Gerontologie und Geriatrie. 2017; 50: 233-238. DOI: $10.1007 / \mathrm{s} 00391-016-1039-8$

34. Meretoja. A, Strbian. D, Putaala. J, et al, SMASH$\mathrm{U}$ : a proposal for etiologic classification of intracerebral hemorrhage, Stroke. 2012; 43: 25922597. https://doi.org/10.1161/ STROKEAHA.112.661603

35. Danesh. A.S, Nojavan. F, Necessity of Menstruation from the Viewpoint of Traditional Traditional Iranian Medicine, Trad Integr Med. 2018; 3: 49-50

36. Ghorbanifar. Z, Farahi. O, Qaraaty. M, Nutritional treatment of abnormal uterine bleeding in Iranian medicine, Trad Integr Med. 2017; 2: 1-2. 